BLS 32, No 1 2006. DOI: http://dx.doi.org/10.3765/bls.v32i1.3452 (published by the Berkeley Linguistics Society and the Linguistic Society of America)

\title{
Remarks on Word-Prosodic Typology
}

\author{
JOSÉ IGNACIO HUALDE \\ University of Illinois at Urbana-Champaign
}

\section{Introduction ${ }^{1}$}

In this paper, I take the typology of word-prosodic systems in Hyman (2005) as a point of departure for the classification of word-prosodic systems. Hyman's proposal is an important one which deserves to be considered very carefully by all researchers in the field. I think this is best done by examining those languages for which there is enough available information and which appear to be problematic or difficult to classify. Here I will focus on Western or Bizkaian Basque-where local prosodic systems range from some extraordinarily similar to Tokyo Japanese (TJ) to others that resemble Spanish to a great extent-and on Palenquero, a Spanish-lexicon creole language of Colombia where Spanish prosody has presumably been influenced and restructured by a Bantu tonal substratum.

Hyman's proposal includes the fundamental insight of choosing two independent parameters - related, respectively, to lexical "headedness" or prominence and to lexical tone - for the typological classification of word-prosodic systems. I think this is correct. Nevertheless, I would like to propose some relatively minor modifications (which, however, result in a rather different classification of some languages).

I would like to suggest that, for the purposes of typological classification, metrical prominence and tone should be treated in a parallel fashion. Following Hyman, a language is tonal to the extent that it offers evidence for specification of tone at the lexical level. Similarly, I would suggest, a language is accentual to the extent that headedness is a word-level feature. In the case of both accent and tone, we may have relatively sparse or relatively dense lexical information; that is, both parameters are continuous. A prototypical tone language has lexical tone on every syllable and several contrasting tones (as in Hyman's examples, Yoruba and Cantonese). In the same way, in a prototypical accent language every word has a metrical head, and there is evidence for more than one lexical level of prominence (as in English). A language like TJ is both less prototypically tonal and less

\footnotetext{
${ }^{1}$ For comments to a version of this paper, I am grateful to Larry Hyman and Gorka Elordieta. All errors are mine.
} 


\section{José Ignacio Hualde}

prototypically accentual. Osaka Japanese is more tonal than TJ, but it does not differ from $\mathrm{TJ}$ along the accent parameter.

In the Autosegmental-Metrical model (Pierrehumbert 1980, Beckman and Pierrehumbert 1988, Ladd 1996), metrical prominence and pitch contours are also carefully distinguished as two different components of prosody. These two components are, however, frequently related, since an effective way to express prominence either at the lexical or the phrasal level is by pitch modulation. That is, syllables that function as metrical heads of words or phrases tend to anchor pitch contours. But there are also languages that disassociate pitch contours from prominence, such as Wolof (Rialland and Robert 2001).

That headedness and lexical tone are independent properties is demonstrated by the fact that a language may lose or significantly alter one of the two properties, keeping the other intact. For instance, whereas many dialects of both Swedish and Serbian/Croatian have both lexically contrastive stress and a lexical tone contrast so that depending on the word a different melody may be associated with the stressed syllable, some dialects of both languages have lost the tonal contrast, but preserve the contrast in terms of which syllable of the word has stress. The same development appears to have taken place in the evolution from Ancient Greek to the modern language, as well as in part of the Central Franconian German/Dutch area (Gussenhoven 2004:228): an original contrast in lexical tone has been lost, without the stress system being affected. The opposite development, a change in the stress assignment rules without an effect on tonal contours, is the origin of the lexical tone contrast in Neo-Štokavian, which is found only in words with initial stress. The reason for this is to be found in a historical retraction of the stress that did not affect pitch contours, so that now peaks are realized very late on the posttonic syllable, except in those words that historically had initial stress (Bethin 1998:162-168). Welsh also appears to have undergone a diachronic leftward shift of the stress without concomitant alteration of the melody, producing here too an unusual association of stressed syllables with tonal contours (Dogil and Williams 1999).

\section{Headedness}

One of the two criteria that Hyman proposes for the typological classification of languages at the highest level is the presence of stress-accent, defined in the following way:

\footnotetext{
A language with stress-accent is one in which there is an indication of word-level metrical structure meeting the following two central criteria:

OBLIGATORINESS: every lexical word has AT LEAST one syllable marked for the highest degree of metrical prominence (primary stress).

CULMINATIVITY: every lexical word has AT MOST one syllable marked for the highest degree of metrical prominence. (Hyman 2005:168, (5))
}

Hyman adds that these two features are not equally important: "obligatoriness is the more important" (2005:169), so that presence of stress-accent, [+SA], can 


\section{Remarks on Word-Prosodic Typology}

be equated with the constraint OBLHEAD (obligatory head) applied to all lexical words in the language. That is, even though Hyman identifies both obligatoriness and culminativity as important properties of stress-accent systems (and considers them independent parameters of prosodic systems, see his table 25), he uses only culminativity for classificatory purposes at the highest level of the typology.

This is an admirably explicit criterion that allows us to easily classify languages for the feature $[ \pm \mathrm{SA}]$. When combined with the second major binary parameter in Hyman's typology, lexical tone, this criterion allows for the typological classification of word-prosodic systems in four major classes (Hyman 2005:172, (14)): (a) [+SA, -tone], e.g. English, Russian; (b) [+SA, +tone], e.g. Swedish/Norwegian, Serbian/Croatian; (c) [-SA, +tone], e.g. Yoruba; and (d) [-SA, -tone], e.g. French, Tamazight Berber.

Notice that the type "accent language", which for Beckman (1986) would include both languages like English and languages like TJ as subtypes (stress-accent vs. non-stress-accent), is not defined in this typology. The fact that languages like TJ and Bizkaian Basque have lexically unaccented words directly excludes them from the $[+\mathrm{SA}]$ class. The correctness of this major typological division should depend on the extent to which languages with a lexical contrast between accented and unaccented words are unlike those in the $[+\mathrm{SA}]$ type in other respects, in addition to the presence/absence of a class of unaccented words. In particular, I think an important question is whether or not the accented words in languages with an accented/unaccented contrast have phonological properties that make them fundamentally unlike the accented words of languages without lexically unaccented words. In the next subsection I will argue for retaining a typological class of "accent languages", more inclusive than Hyman's [+SA] class.

\subsection{Accent in Bizkaian Basque}

In the western Basque region, there is a sort of dialectal prosodic continuum where at one end, in the northern area along the Bizkaian coast (Northern Bizkaian $=\mathrm{NB}$ ), dialects have prosodic systems remarkably similar to TJ, and at the other end we find dialects that are much more similar to Spanish in their prosody, very likely as a result of prosodic convergence in a situation of widespread bilingualism with Basque as the minority language. The existence of this dialectal continuum was taken in Hualde et al. (2002) as an argument for not making a clear-cut distinction between stress-accent and pitch-accent systems. In particular, the only noticeable prosodic difference between some Southern Bizkaian (SB) and some Western Gipuzkoan varieties is the fact that the former dialect group has a class of lexically unaccented words, whereas the latter has only accented words. If the accented syllable of varieties without lexically unaccented words is taken to be a metrical head, it seems reasonable that the same status should be accorded to the accented syllable of the accented words of SB. In this specific case, the presence vs. absence of unaccented words in the lexicon does not seem to be a predictor of any other differences or similarities. The phonetic realization of accent appears to be essentially identical in SB and in Bergara, with both pitch 


\section{José Ignacio Hualde}

and duration (and perhaps also other phonetic cues) as strong correlates (see Etxebarria 1991 for SB). In other words, SB Basque has culminative nonobligatory stress accent.

I believe that even in the most TJ-like NB Basque varieties there are very good reasons for postulating that accented syllables are not simply specified for an invariable tonal contour $\left(\mathrm{H}^{*} \mathrm{~L}\right)$, but are also prosodically prominent. I would like to propose that a lexical indication of pitch on a given syllable should be considered an accent to the extent that:

a. it follows the criterion of culminativity (only one per word domain);

b. it is involved in the expression of pragmatic prominence, so that the syllable bearing it receives special enhancement when the word is pragmatically highlighted in discourse, ${ }^{2}$ and

c. its location is determined by metrical rules.

In the absence of cues other than pitch, I take culminativity (property a) to be a necessary but not sufficient condition. It is sufficient if the syllable bearing the tone is also the locus of prominence at higher levels (property $b$ ). ${ }^{3}$ Its lexical distribution (property c) may provide additional evidence.

In NB Basque, lexical tonal markings (which obey culminativity at the word level: at most one $\mathrm{H}^{*} \mathrm{~L}$ per word) participate in the expression of relative prominence at the phrase level. If the phrase in immediately preverbal position (i.e. focus position) contains more than one lexically accented word, the first accent is generally perceived as more prominent than the others (although experimental evidence is not yet available). Phonetically, we find progressive dowstepping of accents. But non-initial accented words can be given narrow focus, in which case downstep is suspended. On the other hand, lexically unaccented words cannot be highlighted in the same manner (Elordieta 1998, 2003). That is, just like in languages like English, phrasal metrical structure (relations of prominence at the phrasal level) is built upon syllables that are prominent at the word level. The crucial difference is that there are many words that lack a lexical head.

\footnotetext{
${ }^{2}$ As Hyman (2005) notes, besides tonal gestures, languages may have other features that obey the culminative constraint (only one specification per domain). Thus, in Quechua, only one consonant per word may bear contrastive aspiration or glottalization. In my opinion, an important reason not to consider that syllables with aspirated or glottalized consonants in Quechua are accented is that those syllables are not the locus of prominence in discourse. Quechua has word-penultimate stress. Presumably, it is the penultimate syllable that is enhanced when the word is pragmatically highlighted (see O'Rourke 2006).

${ }^{3}$ In stress-accent languages, the domain of stress is usually the syllable, but Lithuanian appears to have a contrast between stress on the whole syllable and stress only on the first mora of the syllable (Dogil and Williams 1999:283). In some tonal accent languages like Somali, the domain of the accent is the mora.
} 
(1) Northern Bizkaian Basque: relations of prominence at the phrasal level

a. $\quad x$

$\mathrm{X} \quad \mathrm{X} \quad \mathrm{X}$

Górkan lagúnen amúma

'Gorka's friends' grandmother' or

'GORKA's friends' (pl.) grandmother'

b.

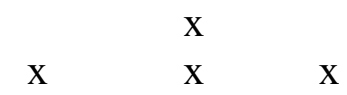

Górkan lagúnen amúma

'Gorka's FRIENDS' grandmother'

c.

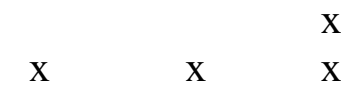

Górkan lagúnen amúma

'Gorka's friends' GRANDMOTHER'

d.

$\mathrm{X}$

Jonen lagunen amúma

'Jon's friend's (sg.) grandmother' = 'JON's friend's grandmother'

$=$ 'Jon's FRIEND's grandmother' = 'Jon's friend's GRANDMOTHER'

It is not just that the overall pitch contour on the focalized word in increased in range, but rather it is the falling contour on the syllable bearing the accent that is enhanced. Consider, for instance, the example illustrated in Fig. 1a (produced by a speaker of from Ondarroa). The preverbal phrase lagunan alabi 'the friend's daughter', whose pitch contour is obligatorily as shown in the figure, could be characterized in purely tonal terms, providing each syllable with one or more tones, as in $(2 \mathrm{a})$ :
a. la gu nan a la bi
b. lagunan alabi
L H H H H HL
$\%$ HH- $\quad \overline{\mathrm{H}} \mathrm{L}$

Figure 1. Ondarroa Basque: lagunan alabi (etorri da) 'The friend's daughter (has arrived)'. (a) Neutral broad focus, (b) Narrow focus.
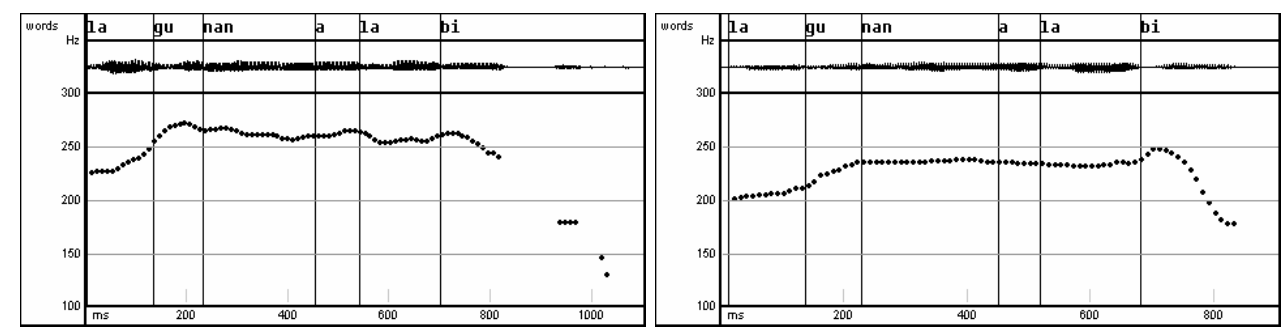


\section{José Ignacio Hualde}

However, if contrastive focus is intended over either the first or the second word of the phrase, it is the pitch contour of the accented syllable that is enhanced, as shown in Figure 1b. That shows that the syllable bearing the HL contour is the locus of prominence. This is not adequately captured by an analysis as in (2a). As just mentioned, words without an accent cannot be highlighted in this way in NB Basque since they lack a prominent syllable (see Hualde et al. 2002:550-551, Elordieta 2003). The emphatic contour in Figure $1 \mathrm{~b}$ is thus ambiguous between contrastive focus on the first word (i.e. 'The FRIEND's daughter has arrived') or the second word (i.e. 'The friend's DAUGHTER has arrived'), or indeed over the whole noun phrase. The accented words of NB Basque thus have the same properties as those of, say, Spanish: when the word is focalized, the accented syllable is made more prominent. The difference is that there are also lexically unaccented words, which do not have a syllable that can be made prominent, such as the word lagunan in the figures. The description of these facts requires reference to the notion of accent, as in (2b) above, which follows Pierrehumbert and Beckman's proposal for TJ (Elordieta 1998, Hualde et al. 2002, etc).

The rules of accent assignment in accented words differ from dialect to dialect, but are always similar to those for stress assignment in stress-accent languages. Thus, in the varieties of the Gernika-Getxo area, only the leftmost accent is realized in polymorphemic words containing more than one accented morpheme, whereas in Markina the general rule is antepenultimate accent (Hualde 2000). ${ }^{4}$ Syllables bearing a $\mathrm{H}^{*} \mathrm{~L}$ contour in Northern Bizkaian Basque thus fulfill the three requirements listed above to be considered prosodic heads.

In summary, both $\mathrm{NB}$ and $\mathrm{SB}$ Basque have culminative but non-obligatory accent. A relevant difference is that NB is very close to the non-stress-accent end of the continuum defined by Beckman (Elordieta and Hualde 2003), whereas SB can be characterized as a language with non-obligatory stress-accent, as argued above.

\subsection{Culminativity with and without Obligatoriness}

Clearly, Hyman's typology could be amended so that it would include a set of accent languages with the two subsets of languages with obligatory (primary) accent and with unaccented words. Still taking the headedness criterion as fundamental, it would be enough to adopt culminativity as the main criterion, with a subdivision according to obligatoriness. In this amended classification, the set of languages with obligatory primary accent on all lexical words, [+oblhead] languages, would be a subset within the larger set of languages with accent in some words, [+headed] languages.

\footnotetext{
${ }^{4}$ When we consider the distribution of accents in $\mathrm{TJ}$ as well, we find rules that are not unlike those responsible for stress assignment in stress-accent languages. Thus, in compounds and derived forms at most one accent is preserved (culminativity). Furthermore, Kubozono (2005) demonstrates that in underived words, once syllable structure is taken into account, what emerges is that the main pattern of accent distribution obeys the Latin rule.
} 


\section{Remarks on Word-Prosodic Typology}

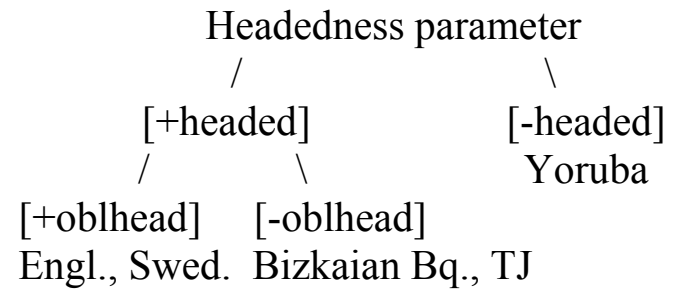

Hyman (2005) considers but rejects the possibility of including obligatory head as a parameter subordinated to culminativity. Instead, he offers a crossclassification of languages with [ \pm culminative] and [ \pm obligatory] as two independent parameters, producing four different types of languages (see his table 25). One problem for subsuming "obligatory head" under "culminativity" that Hyman discusses is Creek, as described by Haas (1977). In Creek, every word has at least one accent (except for light monosyllables), but there are words with more than one accent, e.g. náfka:kís 'they are hitting him', atótkikánks 'he didn't work'. Hyman thus takes Creek as representing the [-culminative, +obligatory] type. It seems to me that more research on Creek is needed in order to determine whether in a word like náfka:kis, both accented syllables have the same level of prominence. For instance, what happens when words with more than one accent are pragmatically highlighted? On the other hand, it is perhaps worth noting that, in Spanish too, adverbs in -mente '-ly', such as complétaménte 'completely' have two stresses whose relative prominence is undetermined.

Whereas the typology in (3), which uses Hyman's criteria in a modified way (giving primary importance to "culminativity"), contains two classes of accent languages, just like Beckman's (1986), the resulting classification is different. Both NB and SB are grouped together in the classification above, since they are accent languages with a class of unaccented words. In Beckman's classification, on the other hand, they would be radically separated along the stress-accent vs. non-stress-accent parameter, since SB uses cues other than pitch for the expression of word-level prominence to a much greater extent than NB.

In the next subsection, I will argue in favor of introducing a further modification to the typological classification in (3). I suggest that languages may vary in the degree to which they employ word-level headedness and that, therefore, a typological classification gains in informativeness if languages are not strictly divided between those that require every word to have a metrical head and those that have unaccented words.

\section{4. "Headedness" as a Non-Binary Parameter}

As Gussenhoven (2006) points out, Beckman's criterion for distinguishing "stress-accent" from "non-stress-accent" languages is gradient, rather than discrete. Gussenhoven proposes to turn it into a binary parameter for classificatory purposes by focusing on whether or not there is a contrast of prominence 


\section{José Ignacio Hualde}

between two types of syllables in contexts where pitch contours are flattened. But the result seems to be that the status of quite a few languages (including Polish, Spanish, Bengali, Turkish, Egyptian Arabic, etc.) becomes undetermined and perhaps undeterminable. ${ }^{5} \mathrm{~A}$ better option may be to recognize that Beckman's parameter is based on phonetic features which are by their very nature gradient.

The presence vs. absence of lexically unaccented words (obligatoriness of word heads), on the other hand, is a phonological parameter that is easy to see as binary. We may, however, turn the table around and see whether we gain in informativeness by recognizing that languages may gradually vary in the extent to which they mark word-level headedness.

Accent languages with a class of unaccented words appear to differ in the lexical importance of the distinction. At one end of a possible typological continuum of accent languages, we would have languages without any unaccented words, and at the other, languages with a lexically robust contrast between accented and unaccented words in all grammatical categories.

Thus, NB Basque varieties have more unaccented words than SB varieties (where only uninflected forms may be unaccented). In some languages the distinction may be restricted to specific categories. If both Somali (Hyman 1981) and $\mathrm{TJ}$ are properly viewed as languages with a contrast between accented and unaccented words, this contrast is more important in TJ than in Somali, where only verbs can be lexically unaccented (Somali nouns can also be unaccented or deaccented in subject position). ${ }^{6}$ In Nubi, the existence of a class of unaccented words is even more marginal, since only "infinitives" are accentless. In fact, Gussenhoven (2006) argues that these accentless words result from a deaccenting rule that applies in certain syntactic contexts.

What it means for a word to be unaccented may also vary across languages. Although the lexical distinction between accented and unaccented words is as robust and phonologically important in NB Basque as in TJ, there is a sense in which unaccented words are more "weakly" unaccented in Basque. This is because Bizkaian Basque has a sentential accent rule. Unaccented words receive an accent in isolation and in sentences where they occur immediately before a verbal participle (unless the verb is focalized). In Gernika Basque (and most other NB varieties), this sentential accent falls on the last syllable of the phrase that receives it. In other positions, including preceding inflected verbs, these words are unaccented. This is shown in (4) for the unaccented nouns gizona 'the man' and alabie 'the daughter':

\footnotetext{
${ }^{5}$ One difficulty is establishing criteria for distinguishing pitch-deaccenting from metrical "beheading" as possibly two distinct phonological processes.

${ }^{6}$ Hyman's (2005) main typology (his table 14) produces the same results for Somali as for Bizkaian Basque and TJ: it is a [+T, $-\mathrm{SA}]$ language. Instead, I find myself in agreement with Hyman's (1981:177) earlier view: “An explanatory account of tone in Somali, therefore, must reveal not only the surface tonal nature of the $\mathrm{H}$ tone, but also its accentual identity with the stressaccents found in English and other languages."
} 


\section{Remarks on Word-Prosodic Typology}

(4)

Gernika NB Basque: lexically unaccented words and sentential accent

a. gizoná 'the man'

gizoná etorri de

'the man has come'

gizona berandú etorri de

'the man has come late'

gizona dá

'it is the man'

gizona datór

'the man is coming'

b. alabié

'the daughter'

alabié etorri de

'the daughter has come'

alabie berandú etorri de

alabie dá

'the daughter has come late'

'it is the daughter'

alabie datór

'the daughter is coming'

Notice that the last syllable of unaccented words is prosodically special in that it is the only syllable that may receive an accent, since accent is phrase-final. What this means is that the representation of these words in the mental lexicon of speakers will contain both tokens where words like gizona and alabie are unaccented and other tokens where their last syllable bears an accent. That is, the last syllable of unaccented words is accentable. This is different from the situation in TJ, where unaccented words never receive an accent. ${ }^{7}$

Consider now the situation in another NB variety, that of Ondarroa. Whereas the accentability under sentential accent of certain syllables (word-final) in lexically unaccented words is predictable in Gernika, in Ondarroa two historical changes have produced a situation where different types of unaccented words actually contrast on the syllable that receives sentential accent. One change, which took place in Ondarroa and other places, was the shift of sentential accents from the final to the penultimate syllable of the phrase (e.g. gizoná > gizóna, alabié > alabie, under sentential accent). The second one was the subsequent loss of final vowels in hiatus (alabie $>$ alabi). The result is illustrated in (5):

Ondarroa NB Basque

a. gizóna

gizóna etorri re

'the man'

gizona berándu etorri re

'the man has come'

gizoná ra

'the man has come late'

gizona rátor

b. alabí

'it is the man'

'the man is coming'

'the daughter'

alabí etorri re

'the daughter has come'

alabi berándu etorri re

'the daughter has come late'

alabí re

'it is the daughter'

alabi rátor

'the daughter is coming'

\footnotetext{
${ }^{7}$ On the other hand, accented words are more accented in Basque, since their accent is realized even after another word with narrow focus (Elordieta and Hualde 2003), a context where accents are deleted in Japanese.
} 


\section{José Ignacio Hualde}

In Ondarroa, thus, there are two classes of unaccented words (depending on whether or not their final vowel was historically deleted): a word like gizona may surface as unaccented in most contexts, or as accented in the context where the sentential accent rule applies. If accented, its accent will be on the penultimate, except in the specific case where only one syllable follows in the accentual phrase, i.e. before the copula $\mathrm{ra}$. On the other hand, the also unaccented word alabi will always receive the sentential accent on its final syllable, as shown above. Since the unpredictability of the position of the sentential accent was brought about by deletion of final vowels in hiatus, one could, of course, make accent assignment look lexically predictable by restoring those final vowels in "underlying representations" (as in Hualde 1996). At the morphophonological level, alabi can indeed be analyzed as /alaba $+\mathrm{a} /$, just like gizona is /gizon+a/. But excluding such abstract analyses, we have to conclude that speakers of Ondarroa Basque need to know which syllable of the word may receive sentential accent for words that surface as unaccented in other contexts. This property must be lexically marked.

Given these facts, one could take the position that either Ondarroa Basque or both Ondarroa and Gernika Basque actually lack a class of unaccented words and that, instead, these languages have a rule deleting certain underlying accents everywhere except in the context of the sentential accent rule. ${ }^{8}$ But that move would produce a typology where TJ and NB Basque (or some subset thereof) end up with quite different characterizations, missing the striking similarity between these prosodic systems. I believe a better option is to take the parameter "obligatory head" as a continuum instead of as a binary feature. In this continuum, NB Basque is a language located farther towards the positive pole than TJ, and SB Basque is located even farther from TJ than the NB varieties. A discussion of Spanish may also be illustrative in this respect.

\subsection{Stressed and Unstressed Function Words in Spanish}

In Spanish, there are no lexically unaccented words belonging to major lexical categories (nouns, adjectives, verbs, and abverbs). Among function words and expressions, on the other hand, we find a lexical contrast between accented and unaccented (or stressed and unstressed) items (Navarro Tomás 1918/1977:187194, Quilis 1993:390-395, Hualde 2005:233-235). ${ }^{9}$ For instance, among determiners, definite articles and possessives are unstressed, but indefinite articles and demonstratives are stressed in standard Peninsular Spanish (e.g. el elefante vs. un elefante).

\footnotetext{
${ }^{8}$ From words in isolation, determining which accents are sentential and thus deleted in other contexts is simple enough for Gernika: an accent on the last syllable is always postlexical (with the only exception of some monosyllables from historical contraction). For Ondarroa, it is more difficult without morphophonological analysis of words. Accents on the final, as in alabi, are always sentential. Accents on the penultimate, on the other hand, may be sentential, as in gizóna, or lexical, as in arbóli 'the tree'.

${ }^{9}$ Navarro Tomás states that there are unstressed adverbs, but he employs a rather broad, traditional definition of "adverb".
} 


\section{Remarks on Word-Prosodic Typology}

The stressed or unstressed status of specific words or classes of words appears to be unpredictable from semantic considerations. In fact, in some cases nearsynonymous expressions differ in stress status:

$$
\begin{aligned}
& \text { Spanish near-synonymous expressions differing in accentability } \\
& \text { en cuanto llegue Juan vs. apenas llegue Juan, } \\
& \text { both 'as soon as Juan arrives' } \\
& \text { puesto que lo sabes vs. dado que lo sabes, } \\
& \text { both 'since you know it' } \\
& \text { aun cuando se lo dije vs. a pesar de que se lo dije, } \\
& \text { both 'even though I told him' }
\end{aligned}
$$

Some unstressed forms minimally contrast with segmentally identical stressed words, as in (7a). There are also words that are stressed or unstressed depending on their syntactic function, as in (7b):

(7) Spanish: contrast between segmentally identical stressed and unstressed forms
a. bajo las sábanas 'I lower the sheets' vs. bajó las sábanas 's/he low- ered the sheets' vs. bajo las sábanas 'under the sheets'
b. más ciruelas 'more prunes' vs. más cincuenta 'plus fifty' menos dinero 'less money' vs. menos dinero 'except for money'

I conclude that the stressed/unstressed contrast is an important one in the phonology of Spanish, even if it is not found in words belonging to the four major word classes. As noted, the accentual properties of function words are not generally predictable from other considerations. ${ }^{10}$ Compared with Bizkaian Basque, Spanish would be a language with only a very limited accented/unaccented contrast, but certainly it is not a language that utterly lacks this lexical contrast.

\subsection{Summary on the Headedness Parameter}

To conclude this section, as stated at the outset, I believe that Hyman's insight of employing headedness as one of two main criteria for typologizing word-prosodic systems is correct. In this section I have suggested that, in order to capture the typological similarities between accentual languages with and without a class of lexically unaccented words, the two aspects of headedness discussed by Hyman, "culminativity" and "obligatoriness", should be considered in a hierarchical relation. Furthermore, I have suggested that the headedness parameter may be more informative if viewed as multivalued rather than as binary. In other words, the proposal is that the relevant typological criterion should be the presence of

\footnotetext{
${ }^{10}$ This fact makes the accented/unaccented contrast particularly difficult in the acquisition of Spanish as a second language, as Navarro Tomás (1918/1977:187) noted. We still do not know how much dialectal variation there is in the accentual status of specific words and word classes.
} 
José Ignacio Hualde

word-level prominence or headedness on one syllable per word. Among languages with this property, the most prototypical ones are those in which every lexical item contains a prosodic head. The existence of more than two levels of prominence among the syllables of a word (as in English) also increases the metrical prototypicality of a language. A language will be less prototypically accentual to the extent that it allows lexically unaccented words.

The extent to which, in languages obeying culminativity, the strength of obligatoriness correlates with Beckman's phonetic stress-accent/non-stress-accent parameter remains an open question and may be a fruitful line of investigation.

\section{Tone}

The second major parameter in Hyman's typological system is the presence of lexical tone: "A language with tone is one in which an indication of pitch enters into the lexical realization of at least some morphemes" (Hyman 2005). Hyman notes that among languages with lexical specification, "prototypical" tone languages are languages like Yoruba and Cantonese, with a high density of lexical tones and several contrasting lexical specifications of pitch, and not languages like TJ or Swedish. But this fact is not directly reflected in his typology. Johnson (2005), who applies Hyman's typological criteria in the typological characterization of Cherokee, also finds it necessary to remark on both the presence of lexical tone and on its low density. In fact, he proposes to distinguish between languages with a dense vs. a sparse tone specification. Clearly, however, we cannot take density vs. sparseness of lexical tone as a binary feature, since in practice there would not be any obvious cut-off point. We may obtain a more informative typology if we modify the binary [ \pm tone] parameter to encode relative tonal density in the typology. Lexical tonal density can be seen as a function of both the maximum number of tonal contrasts that are possible per syllable and the maximum number of syllables per word that can bear lexically contrastive tone. At one end of the typological continuum of languages that would be defined as tonal, we would have a language like Yoruba where every syllable in the word can be specified for one of three contrastive tones. Near the other end, we have a language like Neo-Štokavian Serbian/Croatian/Bosnian, where an indication of lexical-level pitch is found only in words with initial stress-accent. In these words the stress-accented syllable may be specified for either an earlier or a later tonal peak (capturable as $\mathrm{L}^{*} \mathrm{H}$ vs. $\mathrm{LH}^{*}$, cf. Smiljanić 2002). Words with non-initial stress-accent lack this contrast.

\subsection{Languages with Sparse and Possibly Redundant Tonal Specifications}

In the case of some languages with sparse tonal specification, controversies have often arisen regarding their analysis and proper characterization. In some sparsetone accent languages like Swedish, Belgrade Serbian, Maastricht Dutch, Osaka Japanese, etc., it seems clear that both tone and accent must enter into the lexical specification of words. In these languages, knowing which syllable is accented or whether the word is accented or unaccented is not enough to determine the 


\section{Remarks on Word-Prosodic Typology}

prosody of the word.

On the other hand, languages like Nubi, TJ, and NB Basque could in principle be analyzed as having lexical specification only for tone, only for accent, or redundantly for both. This is because at most one syllable per word needs to be specified per tone, and the tonal specification is, furthermore, the same for all words.

In $\S 2.1$, I argued that NB Basque should be considered to be a language with (non-obligatory) lexical accent. At the same time, there are reasons for concluding that the tonal specification of accented words should also be part of the lexical representation of accented words even if its shape is predictably $\mathrm{H}^{*} \mathrm{~L}$, since this contour is in fact the only constant and significant cue for the accent. Languages like NB Basque (and TJ) have redundant lexical specification for accent and tone. This is similar to the position taken by Gussenhoven (2004:185): "Northern Bizkaian Basque and Tokyo Japanese are tone languages, with lexically distinctive accent."

Nubi is clearly an accent language, with many prosodic properties in common with stress-accent languages (Gussenhoven 2006). The single prosodically prominent syllable of every word is located within the same three-syllable window that we find in languages like Spanish and Greek. Furthermore, in Nubi there is a rule of accent retraction similar to those found in other accentual languages. Unlike TJ, Nubi does not have a class of lexically unaccented words. Also, unlike in TJ, tone is not the only correlate of accent. In Nubi, accented syllables, besides bearing an $\mathrm{H}$ tone, are also characterized by duration and possibly other acoustic features. Nubi is thus further away from the non-stress-accent prototype of Beckman's (1986) classification of accent languages than TJ. Even if pitch is the most important cue of accent in Nubi, this is also the case in many other languages that we may want to classify as non-tonal stress-accent languages, such as Turkish and Polish. Whether the invariant (and therefore not paradigmatically contrastive) $\mathrm{H}$ tone born by the accented syllable of all words in Nubi is also lexical is less evident. The argument that Gussenhoven offers for considering Nubi a language with lexical tone is that accented syllables in Nubi systematically occur with an $\mathrm{H}$ tone. This $\mathrm{H}$ tone, being obligatory, cannot be said to be part of the utterance-level intonational component of the language (cf. Hyman 1981 for Somali). To determine this issue, it would be useful to systematically compare Nubi with its lexifier language, Egyptian Arabic, which has also been claimed to mark the head of every word in an utterance with a rise in pitch (Hellmuth 2005). Here, instead, I will consider the comparable case of Palenquero, a Spanishlexified creole spoken in Colombia.

\subsection{Palenquero vs. Argentinean Spanish}

Researchers working on Palenquero have often remarked that its prosody is strikingly different from that of the coastal Colombian Spanish varieties with which it is in contact. Several linguists have claimed that Palenquero has lexical tone (Bickerton and Escalante 1970) or a tonal accent (Moñino 2001). Hualde and 


\section{José Ignacio Hualde}

Schwegler (to appear) point out several prosodic features in which Palenquero differs from Spanish, including the rather systematic association of accented syllables with level $\mathrm{H}$ tones (and other syllables with $\mathrm{L}$ tones), the small declination effects, and the frequent absence of final falls in declaratives with an accent on the final syllable. These properties are illustrated in Figure 2 (for further exemplification, see Hualde and Schwegler, to appear). Perhaps not surprisingly, similar facts have been noted for Equatorial Guinea Spanish, whose speakers are almost all native speakers of a Bantu tonal language (Quilis and Casado Fresnillo 1995, Lipski 2005).

Figure 2. Palenquero yó sí tén maílo nú 'I sure don't have a husband'

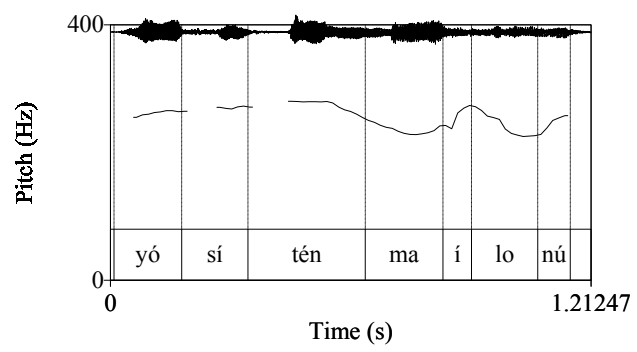

Regarding accent, Palenquero shows essentially the same evidence for lexical heads as Spanish, since the patterns of prominence are virtually identical in both languages. The question is whether, in addition, tone should also be taken to be a lexical property in Palenquero. Of the differences between Spanish and Palenquero mentioned above, some are clearly differences in their postlexical or phrasal prosody. The rather systematic association of $\mathrm{H}$ tone with accented syllables, however, could in principle be taken as evidence for postulating that accented syllables are (redundantly) specified for an $\mathrm{H}$ tone in the lexicon, just as Gussenhoven (2006) claims for Nubi. ${ }^{11}$ In this respect, Palenquero differs from most varieties of Spanish where stress-accented syllables may be associated with one of several different pitch contours (although the inventory of pitch-accents is not as rich as in English, see Beckman et al. 2002). However, there are also Spanish dialects where stress-accented syllables almost always show a tonal peak (leaving aside the case of Equatorial Guinea Spanish). In particular, Barjam (2004) analyzes Buenos Aires Spanish as having only two pitch-accents in its inventory, $/ \mathrm{L}+\mathrm{H}^{*} /$ and $/ \mathrm{L}+\wedge \mathrm{H}^{*} /$. Both are rising pitch accents and differ only in the fact that in $/ \mathrm{L}^{+} \mathrm{H}^{*} /$ the $\mathrm{H}$ tone is upstepped. These phonological pitch-accents have several "allotones", but in all of them there is an $\mathrm{H}^{*}$ associated with the stressed syllable. The only case where a word may lack an $\mathrm{H}^{*}$ tone on its stressed

\footnotetext{
${ }^{11}$ Lipski (2005:212) also makes the claim that Equatorial Guinea Spanish has lexical tone: "In the case of Spanish as phonologically restructured by speakers of Bantu languages in Equatorial Guinea (all of which use a basic two-tone system), it appears that many instances of lexical stress accent in Spanish have been reinterpreted as lexically preattached High tone."
} 


\section{Remarks on Word-Prosodic Typology}

syllable is in contexts of pragmatic deaccentuation, but even this is only an optional phenomenon. Barjam's analysis is consistent with other descriptions of Buenos Aires Spanish that have noted that this variety lacks the displacement of peaks to the post-tonic in words in prenuclear position that is typical of most Spanish dialects (Colantoni and Gurlekian 2004). Given the constancy of the $\mathrm{H}^{*}$ tone on the stressed syllable across intonational contexts in Buenos Aires Spanish, one could attribute this tone to the lexical specification of words. That is, both for Palenquero and for Buenos Aires Spanish, we could have an analysis where function words are either $\mathrm{H}$-toned or toneless and lexical words obligatorily bear a single $\mathrm{H}$ tone (on one of the last three syllables of the word). I think it is appropriate to wonder, then, why analyses involving a lexical $\mathrm{H}$ have been suggested for Palenquero and Nubi (and Equatorial Guinea Spanish), but not for Buenos Aires Spanish. Comparing Palenquero and Buenos Aires Spanish, I would like to suggest that the reason has to do with the relative contribution of the necessarily postlexical intonational component to the overall pitch contours of utterances.

Both Palenquero and Equatorial Guinea Spanish utterances appear to have more "ups and downs" in pitch than equivalent utterances in "standard Spanish" varieties, including Buenos Aires Spanish; that is, between H-toned accented syllables, the tone tends to stay low with more abrupt rises and falls, as can be seen on the contour borne by mailo 'husband' in Figure 2. Palenquero may seem more "tonal" because it makes more sparse use of boundary tones (as noted, these may even be absent at the end of declarative utterances accented on their final syllable). In addition, the two rising accents that Barjam (2004) postulates for Buenos Aires Spanish are subject to considerable pragmatically based allotony. In contrast, the pitch patterns of words in Palenquero appear to be relatively constant regardless of pragmatic factors. Other differences may have to do with rules of phonetic implementation. The relative contribution of pitch and other phonetic features to the marking of accented syllables may also determine the overall impression of the language.

It seems reasonable to conclude that in languages without lexical contrasts in tone, pitch specifications may be said to be lexicalized to different degrees. Whether or not the language has a class of unaccented words is an independent fact. The same issues arise in Bizkaian Basque varieties. Thus, for NB Basque, the accentual $\mathrm{H}^{*} \mathrm{~L}$ is a consistent feature of accented words and is perhaps the only consistent correlate of accent for many speakers. These are good reasons for taking this invariable tonal contour as lexical. For SB Basque, on the other hand, there are less compelling reasons for postulating lexical specification of tones, since accented syllables are also made prominent by increased duration (and it remains to be demonstrated that accents have an invariable contour).

\section{Conclusion}

As recognized in the Autosegmental-Metrical model, tonal autosegments and metrical constituency are two independent (but often related) and fundamental aspects of prosody. A typology of word-prosodic systems based on these two 
José Ignacio Hualde

parameters, as in Hyman's (2005) proposal, is particularly appealing. In the modified proposal put forward in this paper, both parameters are treated in a parallel fashion: the presence of word-level marking on either the metrical or the tonal tier (or both) is what determines the basic grouping of languages.

In tone languages, there is lexical marking of pitch, as in Hyman's proposal. Accent languages are also those in which metrical prominence (headedness) is indicated at the word level to some degree. Tonal-accent languages are those with word-level marking on both tiers. Just as there is widespread recognition that tonal density is an important continuous feature in any typology, here it has been proposed that metrical headedness should be treated in the same way, with languages with obligatory lexical marking of heads and evidence for several lexical levels of prominence (such as English) as the prototype that corresponds, along the tonal parameter, to languages like Yoruba and Cantonese, with marking of tone on every syllable and several contrasting lexical tones.

\section{References}

Azkue, Resurrección M. 1923. Morfología vasca. Bilbao: Euskaltzaindia. Reprinted 1969 in Editorial La Gran Enciclopedia Vasca, Vol. 3, Bilbao.

Azkue, Resurrección M. 1931-1932. Del acento vasco en algunos de sus dialectos. Euskera 4:282-318, 6:3-50.

Barjam, John Patrick. 2004. The Intonational Phonology of Porteño Spanish. M.A. diss., University of California at Los Angeles.

Beckman, Mary. 1986. Stress and Non-Stress Accent. Dordrecht: Foris.

Beckman, Mary, Manuel Díaz-Campos, Julia T. McGory, and Terrell Morgan. 2002. Intonation Across Spanish in the Tones and Break Indices Framework. Probus 14:9-36.

Bethin, Christina. 1998. Slavic Prosody: Language Change and Prosodic Theory. Cambridge: Cambridge University Press.

Bickerton, Derek, and A. Escalante. 1970. Palenquero: A Spanish-Based Creole of Northern Colombia. Lingua 24:254-267.

Bruce, Gösta, and Ben Hermans. 1999. Word Tone in Germanic Languages. In Harry van der Hulst, ed., Word Prosodic Systems in the Languages of Europe, 605-658. Berlin: Mouton de Gruyter.

Colantoni, Laura, and Jorge Gurlekian. 2004. Convergence and Intonation: Historical Evidence from Buenos Aires Spanish. Bilingualism: Language and Cognition 7(2):107-119.

Díaz-Campos, Manuel. 2000. The Phonetic Manifestation of Secondary Stress in Spanish. In Héctor Campos, Elena Herberger, Alfonso Morales-Front, and Thomas J. Walsh, eds., Hispanic Linguistics at the Turn of the Millennium, 49-65. Somerville, MA: Cascadilla Press.

Dogil, Grzegorz, and Briony Williams. 1999. The Phonetic Manifestation of Word Stress. In Harry van der Hulst, ed., Word Prosodic Systems in the Lan- 


\section{Remarks on Word-Prosodic Typology}

guages of Europe, 273-334. Berlin: Mouton de Gruyter.

Elordieta, Gorka. 1998. Intonation in a Pitch Accent Variety of Basque. Anuario del Seminario de Filología Vasca 'Julio de Urquijo' 32:511-669.

Elordieta, Gorka. 2003. Intonation. In José I. Hualde and Jon Ortiz de Urbina, eds., A Grammar of Basque, 72-112. Berlin: Mouton de Gruyter.

Elordieta, Gorka, and José I. Hualde. 2003. Tonal and Durational Correlates of Accent in Context of Downstep in Lekeitio Basque. Journal of the International Phonetic Association 33:195-209.

Etxebarria Ayesta, Juan Manuel. 1999. Zeberio haraneko euskararen azterketa etno-linguistikoa. Zornotza (Euba): I.K.A.

Gussenhoven, Carlos. 2004. The Phonology of Tone and Intonation. Cambridge: Cambridge University Press.

Gussenhoven, Carlos. 2006. The Prosody of Nubi between Stress and Tone. Phonology [to appear].

Hass, Mary R. 1977. Tonal Accent in Creek. In Larry M. Hyman, ed., Studies in Stress and Accent (Southern California Occasional Papers in Linguistics 4), 195-208. Department of Linguistics, University of Southern California.

Hellmuth, Sam. 2005. Every Word Has One: Intonational Pitch Accent Distribution in Cairene Arabic. Paper presented at the Between Stress and Tone Conference, Leiden.

Hualde, José I. 1996. Accentuation and Empty Vowels in Ondarroa Basque: Against the Concept of Phonological Derivation. Lingua 99:197-206.

Hualde, José I. 2000. On System-Driven Sound Change: Accent Shift in Markina Basque. Lingua 110:99-129.

Hualde, José I. 2005. The Sounds of Spanish. Cambridge: Cambridge University Press.

Hualde, José I., Gorka Elordieta, Iñaki Gaminde, and Rajka Smiljanić. 2002. From Pitch-Accent to Stress-Accent in Basque. In Carlos Gussenhoven and Natasha Warner, eds., Laboratory Phonology VII, 547-584. Berlin: Mouton de Gruyter.

Hualde, José I., and Armin Schwegler. To appear. Intonation in Palenquero. Journal of Pidgin and Creole Languages.

Hyman, Larry M. 1981. Tonal Accent in Somali. Studies in African Linguistics 12:169-203.

Hyman, Larry M. 2005. Word-Prosodic Typology. UC Berkeley Phonology Lab Annual Report 2005, 165-184. To appear in Phonology. http://linguistics.berkeley.edu/phonlab/annual_report_2005.html.

Johnson, Keith. 2005. Tone and Pitch Accent in Cherokee Nouns. UC Berkeley Phonology Lab Annual Report 2005, 1-48.

Kubozono, Haruo. 2005. Where Does Loanword Prosody Come From? A Case Study of Japanese Loanword Accent. Lingua [to appear].

Ladd, D. Robert. 1996. Intonational Phonology. Cambridge: Cambridge University Press.

Levi, Susannah. 2005. Acoustic Correlates of Lexical Accent in Turkish. Journal 
José Ignacio Hualde

of the International Phonetic Association 35(1):73-97.

Lipski, J. 2005. A History of Afro-Hispanic Language. Cambridge: Cambridge University Press.

Moñino, Yves. 2001. Le palenquero de Colombia: langue accentuelle ou langue tonale? Paper presented at ACPBLE, Coimbra, Portugal.

Navarro Tomás, Tomás. 1977 [1918]. Manual de pronunciación española, 19th edition. Madrid: Consejo Superior de Investigaciones Científicas (Publicaciones de la Revista de Filología Española [4th edition, 1932]).

O'Rourke, Erin. 2006. An Instrumental Analysis of Quechua Intonation: Statements and Questions. Ms., University of Pittsburgh.

Pierrehumbert, J. 1980. The Phonology and Phonetics of English Intonation. Ph.D. diss., Massachusetts Institute of Technology.

Pierrehumbert, Janet, and Mary E. Beckman. 1988. Japanese Tone Structure. Cambridge, MA: MIT Press.

Quilis, Antonio. 1993. Tratado de fonología y fonética españolas. Madrid: Gredos. Quilis, Antonio, and Celia Casado-Fresnillo. 1995. La lengua española en Guinea Ecuatorial. Madrid: Universidad Nacional de Educación a Distancia.

Rialland, Annie, and Stéphanie Robert. 2001. The Intonational System of Wolof. Linguistics 39:893-939.

Smiljanić, Rajka. 2002. Lexical, Pragmatic and Positional Effects on Prosody in Two Dialects of Croatian and Serbian: An Acoustic Study. Ph.D. diss., University of Illinois at Urbana-Champaign. Published 2004 in Outstanding Dissertations in Linguistics, New York, Routledge.

José Ignacio Hualde

Department of Spanish, Italian and Portuguese, 4080 FLB

University of Illinois at Urbana-Champaign

Urbana, IL 61801

jihualde@uiuc.edu 